\title{
Paving the road for improved integrative investigations of past Warm Extremes
}

\author{
Emilie Capron ${ }^{1,2}$, A. Govin³, P. Bakker ${ }^{4}$, J.S. Hoffman4, M. Holloway ${ }^{1,5}$, G. Moseley ${ }^{6}$ and E. J. Stone ${ }^{5}$ \\ Cambridge, UK, 9-11 November 2015
}

The Last Interglacial (LIG, 129-116 ka) and Marine Isotopic Stage 11 (MIS 11, 424-374 ka) stand out as warm interglacials in the context of the last $800 \mathrm{ka}$ (PIGS Working Group 2016). During the first workshop of PAGES Quaternary Interglacials (QUIGS) working group, a multi-disciplinary group of 31 delegates assessed the current knowledge and research needs on the temporal and spatial patterns of climate forcing, responses and feedbacks during these warm extremes.

Presentations and discussions around recent work (new climate proxies and paleoclimatic records, data syntheses, and climate simulations) outlined known features of the LIG and MIS 11 climates. Overall, the LIG was characterized by sea level 6-9 $\mathrm{m}$ higher and warmer temperatures than present-day almost everywhere over the globe. However, peak warmth did not occur synchronously across the globe and it is unlikely orbital forcing explains the observed warmth at all locations. During MIS 11, sea level reached 6-13 m higher than present day and many locations experienced prolonged warmth. Still, the magnitude and drivers of enhanced warmth during LIG and MIS 11 remain unclear.

The workshop also identified current limitations, critical missing datasets and research needs for both interglacials. We need to move toward quantitative estimates of MIS 11 and LIG global warmth and spatio-temporal climate evolutions, via new data compilations and advanced model-data comparisons. Future data syntheses should (1) better assess the seasonality of proxy records to improve interpretation of temperature reconstructions, (2) use robust and coherent chronologies amongst climatic records derived from different archives and a full integration of uncertain ties on ages and tracers, (3) better integrate terrestrial records, and (4) be extended to parameters other than temperature (e.g. isotopic tracers). The latter is particularly important, since a number of climate models now have the ability to explicitly simulate climate proxies. Finally, diagnosing unambiguously the state of the Antarctic and Greenland ice sheets during these warm extremes remains a major challenge essential to assess their respective contribution to the recorded higher sea levels.

Setting guidelines for climate simulations to be performed during Phase 6 of the Coupled Model and Ice Sheet Model Intercomparison Projects (CMIP6, ISMIP6) and Phase 4 of the Paleoclimate Model Intercomparison Project (PMIP4) were also discussed. The coordinated
CMIP6/ISMIP6/PMIP4 core simulation will be run at $127 \mathrm{ka}$, which was identified as the most appropriate time interval to determine LIG climate responses and feedbacks to strong insolation forcing (Fig.1). Simulated climate will be compared to data time series between 128-125 ka to account for delays in climate responses as well as age uncertainties. The $127 \mathrm{ka}$ experiment design will be detailed in a paper to be submitted later in 2016 to the Climate of the Past CMIP6 special issue. Additional sensitivity simulations will be performed within PMIP4 e.g. (1) 127 ka snapshot simulations will investigate the effect of (i) Heinrich event 11 freshwater input and (ii) an early West Antarctic Ice Sheet collapse, (2) a 116 ka snapshot simulation to explore glacial inception processes, (3) MIS 11 snapshot simulations at $416 \mathrm{ka}$ and $409 \mathrm{ka}$.

The next QUIGS workshop in October (http:// pastglobalchanges.org/calendar/upcoming/127-pages/1592-2nd-quigs-wshop ) will focus on the timing and shape of glacial Terminations.

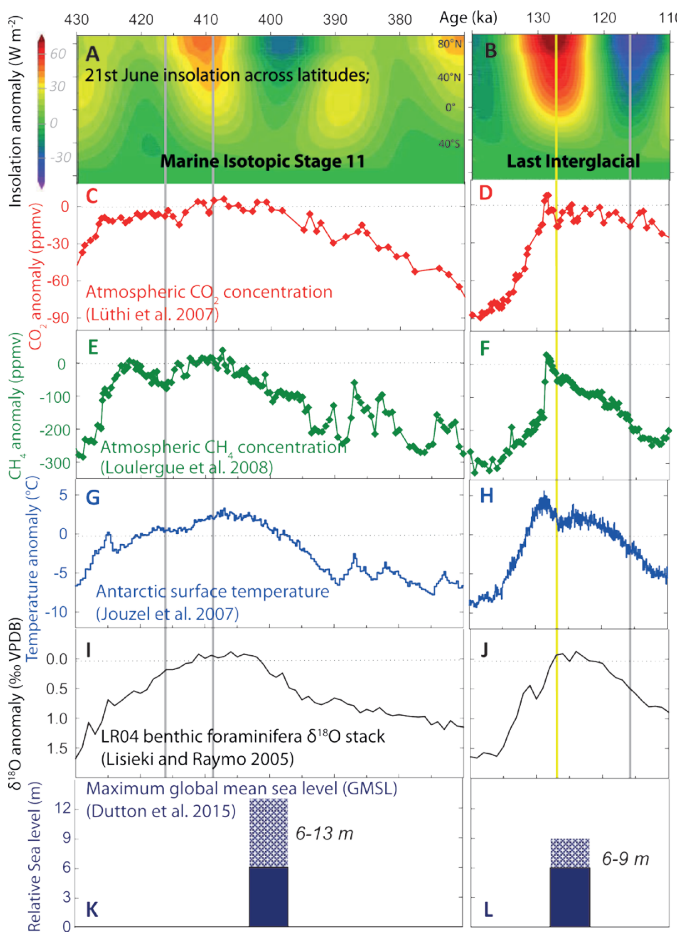

Figure 1: Forcing and climatic records across Marine Isotopic Stage 11 and the LIG. Anomalies for A-J are relative to the average value of the last 1000 years, and to present day for $\mathbf{K}-\mathbf{L}$. Ice core records are displayed in panels $\mathbf{C}$-H on the AICC2012 chronology (Bazin et al. 2012; Veres et al. 2012), the LR04 benthic $\delta^{18} \mathrm{O}$ curve on its independent chronology (Lisiecki and Raymo 2005). Vertical yellow line indicates $127 \mathrm{ka}$, the time interval chose to run the coordinated CMIP6/ISMIP6/PMIP4 core simulation and the vertical grey lines represent the 116, 409 and $416 \mathrm{ka}$, time intervals for which additional PMIP4 sensitivity simulations will be run. (K-L) Maximum global mean sea level (GMSL) relative to present-day, uncertainties remain both in the amplitude (indicated by the shading) and in the exact timing of the GMSL peaks for each interglacial. 